\title{
A Dryline in Southeast Wyoming. Part II: Airborne In Situ and Raman Lidar Observations
}

\author{
Philip T. Bergmaier, Bart Geerts, Zhien Wang, Bo LiU, And PATrick C. CAMPbell \\ Department of Atmospheric Science, University of Wyoming, Laramie, Wyoming
}

(Manuscript received 3 October 2013, in final form 23 March 2014)

\begin{abstract}
Part I of this study describes the mesoscale structure of a dryline over southeastern Wyoming. This dryline formed just east of the western rim of the high plains on 22 June 2010 and became more defined as it progressed eastward during the afternoon. Part I also describes the numerically simulated structure and evolution of this dryline and the observed initiation of deep convection in the vicinity of the dryline.

An instrumented aircraft, the University of Wyoming King Air, repeatedly flew across this dryline, mostly low enough to penetrate the moist-air wedge east of the dryline. Flight-level in situ data along these low-level penetrations indicate relatively high values of convective available potential energy (CAPE; $>1500 \mathrm{~J} \mathrm{~kg}^{-1}$ ), yet low convective inhibition, within a few kilometers of the dryline. Water vapor transects obtained from a compact nadir-pointing Raman lidar aboard the aircraft reveal an extremely sharp humidity gradient below flight level along the dryline, coinciding with the fineline seen in operational weather radar base reflectivity imagery. They also reveal several plumes of higher specific humidity within the dry elevated mixed layer above the moistair wedge, possibly precursors of cumulus clouds. The vertical structure of the dryline revealed by Raman lidar and the flight-level data correspond well to that in the high-resolution numerical simulation.
\end{abstract}

\section{Introduction}

Mesoscale moisture boundaries known as drylines frequently appear over the southern Great Plains of the United States during the spring and early summer months (NSSP Staff 1963; Rhea 1966; Schaefer 1986). Occasionally, drylines are observed farther north as well (Fujita 1958; Taylor et al. 2011). This study focuses on a dryline observed in southeast (SE) Wyoming (WY) on 22 June 2010. The mesoscale structure of this dryline was documented in Campbell et al. (2014, hereafter referred to as Part I), using operational observations and a Weather Research and Forecasting Model (WRF) simulation with inner domain resolution of $1 \mathrm{~km}$. This paper (Part II) examines airborne Raman lidar and flight-level data obtained across the same dryline by the University of Wyoming King Air (UWKA) research aircraft. This dryline developed under "synoptically active" conditions, whereby the development, intensity, and motion of the dryline are heavily influenced by the synoptic environment. The afternoon of 22 June 2010 was characterized

Corresponding author address: Philip T. Bergmaier, Dept. of Atmospheric Science, University of Wyoming, 1000 East University Ave., Laramie, WY 82071.

E-mail: pbergmai@uwyo.edu by a developing surface lee cyclone in eastern Colorado and a weak 500-hPa shortwave over the western United States. The reader is directed to Part I for further description of the synoptic conditions and an analysis of the meso$\gamma$-scale horizontal and vertical structure of this dryline.

Interest in drylines generally stems from their connection with the initiation and subsequent development of deep convection (Rhea 1966). Numerous studies (Koch and McCarthy 1982; Hane et al. 1993, 1997; Ziegler et al. 1997; Ziegler and Rasmussen 1998; Xue and Martin 2006a,b; Wakimoto et al. 2006; Murphey et al. 2006; Wakimoto and Murphey 2009), many of them emerging from the 2002 International $\mathrm{H}_{2} \mathrm{O}$ Project (IHOP) (Weckwerth et al. 2004), have investigated the role that drylines play in the initiation of deep convection (CI). In general, it is thought that local deepening of the moist boundary layer near or just east of the dryline effectively eliminates convective inhibition (CIN) and maximizes convective available potential energy (CAPE). This deepening is due to circulations at a scale larger than that of convective thermals, such as horizontal convective rolls (HCRs). The resulting lifting of the capping inversion then allows the boundary layer air to more easily reach its lifting condensation level (LCL) and level of free convection (LFC) without being eroded by entrainment in the dry, sheared environment above the 
moist boundary layer (Ziegler et al. 1997; Ziegler and Rasmussen 1998). Boundary layer thermals will assist in this process, but they operate at smaller scales in time and space. Model output presented in Part I suggests that local convergence associated with HCRs and smallscale cyclonic vortices along the dryline may have been responsible for local deepening of the moist boundary layer on 22 June, leading to CI. Observations and modeling work lend support to the notion that HCRs and misocyclones can influence CI near drylines (e.g., Atkins et al. 1998; Xue and Martin 2006a; Murphey et al. 2006), although other processes may impact drylinerelated CI, including enhanced vertical motion due to the intersection of the dryline with a baroclinic boundary (Parsons et al. 2000; Weiss and Bluestein 2002), gravity waves (Koch and McCarthy 1982; Wakimoto et al. 2006), and the thermally forced mountain-plain circulation (Part I). Many of these processes operate on small spatial and temporal scales and may go undetected by even the densest network of surface observations. For this reason, the use of both mobile and airborne remote sensing instrumentation has become more common in recent years in the effort to capture these processes in action. A number of studies have made use of groundbased (e.g., Parsons et al. 1991, 2000) and airborne (e.g., Wakimoto et al. 2006; Murphey et al. 2006) lidars to resolve the structure of drylines in greater detail.

The goal of this study is to describe the finescale vertical structure of a dryline in SE Wyoming and elucidate the finescale dynamics that may lead to CI. This study will provide further evidence corroborating two key arguments put forth in Part I: first, that well-defined drylines do indeed occur in Wyoming, and second, that drylines may be instrumental in CI as CAPE is substantial, yet CIN is weak (compared to farther east) within a few kilometers of the dryline. The data presented herein are unique in the sense that they include the first airborne Raman lidar vertical transects across a dryline, transects that capture the dryline at very fine vertical and along-track scales.

Section 2 provides details of the Raman lidar and describes some of the UWKA instrumentation, while section 3 gives an analysis of the data, including a discussion of the lidar transects and a comparison with model output from Part I. Finally, sections 4 and 5 will present a more general discussion and the main conclusions, respectively.

\section{Data sources}

\section{a. Compact Raman lidar}

As part of the 2010 Wyoming King Air PBL Exploratory Experiment (KAPEE), the UWKA carried a Raman lidar that provides vertical profiles of aerosol backscatter and water vapor mixing ratio below flight level. This lidar was designed to be powerful enough to provide a measurable Raman scattering signal during daylight, yet compact enough to fit on a small aircraft and operate in synergy with other instruments on board. The Raman technique operates by transmitting a pulse of laser light at a fixed wavelength and simultaneously recording signals at wavelengths corresponding to the inelastic Raman shifts of nitrogen and water vapor. Raman lidars have operated on aircraft before (e.g., Heaps and Burris 1996; Whiteman et al. 2010), but these lidars were not as compact and low power as the one used in this study.

The transmitter of the UWKA compact Raman lidar is a flashlamp-pumped $\mathrm{Nd}$ :YAG laser that emits about $50 \mathrm{~mJ}$ for every pulse at $355 \mathrm{~nm}$ with a repetition rate of $30 \mathrm{~Hz}$. The $355-\mathrm{nm}$ wavelength is chosen as a result of lower background radiation, stronger excited Raman scattering, and higher eye safety than longer wavelengths. The emitted laser beamwidth is reduced to $0.4 \mathrm{mrad}$ by 10 -times beam expanders. The receiver is a Cassegrain telescope with a $30-\mathrm{cm}$ aperture primary mirror. A shading tube blocks most of the incoming daylight, and the telescope's secondary mirror is mounted on the top of this tube. The analog-to-digital data system simultaneously records four channels, that is, elastic scattering (parallel and perpendicular) and Raman scattering from water vapor $(407 \mathrm{~nm})$ and nitrogen $(386 \mathrm{~nm})$.

The width of the close-range lidar blind zone can be reduced by widening the field of view, but that also yields much background noise at any range. Noise can be suppressed by time averaging, but that reduces the time resolution. Clearly there are trade-offs. We opted for a narrow blind zone, to optimize comparison with flight-level humidity measurements, and for limited time averaging, to allow high along-track spatial resolution. Therefore, and because of its low pulse power, the UWKA compact Raman lidar is quite range limited. The maximum range for water vapor is about $600 \mathrm{~m}$ during the daytime. The capability of far-range detection is not as vital for an airborne profiling system as for a scanning ground-based system. The lidar's range resolution $(\Delta z)$ is $0.75 \mathrm{~m}$, and at $30 \mathrm{~Hz}$ the along-track sampling rate $(\Delta x)$ is $3 \mathrm{~m}$ for the UWKA speed $\left(\sim 85 \mathrm{~m} \mathrm{~s}^{-1}\right)$. The spatial resolution of the retrieved water vapor mixing ratio is larger, given the need to average. The amount of averaging is based on theoretical studies of the Raman lidar noise and error estimation (Whiteman et al. 2001; Di Girolamo et al. 2006), which have been verified with our own Raman lidar measurements (B. Liu et al. 2014, unpublished manuscript). The same random error can be maintained with 
different combinations of $\Delta z$ and $\Delta x$ for a set value of the product $\Delta z \Delta x$. In the Raman water vapor analysis presented herein, the horizontal (vertical) resolution is about $500 \mathrm{~m}(30 \mathrm{~m})$, which corresponds with a $5 \%$ uncertainty in mixing ratio to a range of $500 \mathrm{~m}$ during the daytime. Further technical information about this Raman lidar, including the water vapor retrieval algorithm and the calibration method, can be found in a future paper by B. Liu et al. (2014, unpublished manuscript). That paper also shows a comparison with flight-level humidity measurements and an example of water vapor profile uncertainty as a function of the range below the aircraft.

\section{b. Other data}

The UWKA also carried a suite of in situ atmospheric probes, measuring wind, temperature, and humidity at high temporal resolution, cloud liquid water, and hemispheric visible and infrared radiation. Specific humidity was measured with a LI-COR 6262 probe, which is a high-rate $(>25 \mathrm{~Hz})$ instrument, calibrated in flight by means of the very accurate but slow-response Cambridge chilled mirror dewpoint probe.

This study also uses level II Weather Surveillance Radar 88-Doppler (WSR-88D) reflectivity data and Geostationary Operational Environmental Satellite-13 (GOES-13) visible satellite data at $1-\mathrm{km}$ resolution. It also uses the inner domain (1-km resolution) model output from the WRF simulation described and analyzed in Part I. But the emphasis of this study is on airborne measurements. Data were processed in Interactive Data Language (IDL) and displayed using both IDL and the Integrated Data Viewer (IDV), developed by Unidata.

\section{Dryline analysis}

On 22 June 2010, the UWKA research aircraft completed a 2-h, 26-min flight (1946-2212 UTC) in SE Wyoming during which airborne data were collected across a dryline. Satellite observations indicate that shallow convection had initiated in the form of cumulus near this dryline as early as 1825 UTC (not shown) with isolated deep convection (defined both in Part I and here in Part II as a cell with radar echoes in excess of $40 \mathrm{dBZ}$ ) first observed $15 \mathrm{~km}$ east of the dryline at 2015 UTC to the northwest of the Cheyenne WSR-88D (KCYS) (see Fig. 7a in Part I), that is, about $30 \mathrm{~min}$ before the first UWKA flight transect. This section will examine data from a number of these transects, or flight legs, which crossed either through or just above the dryline. The lowest flight legs sampled the moist, unstable environment to the east, from which the deep convection originated. The first thunderstorm that afternoon had erupted just before the UWKA started sampling the dryline. Some evidence will be shown that suggests that the boundary layer moisture field along one flight leg may have been "contaminated" by outflow from this earlier convection. Photographs from a forward-pointing camera aboard the UWKA (not shown) indicate that no clouds were actually penetrated by the aircraft during the flight, although several flight legs clearly flew below low-based cumulus near or just east of the moisture boundary.

\section{a. Flight-track mapping}

The complete UWKA flight track is plotted on a topographic background in Fig. 1. The flight track, colored by in situ specific humidity $\left(q_{v}\right)$ measurements, allow for easy identification of the location of the moisture boundary (i.e., strongest moisture gradient), although once the UWKA flew too high to penetrate into the moist boundary layer. The higher terrain west of KCYS is the Laramie Range, a broad north-to-south ridge and the western rim of the high plains just to the east. This rim blocked the westward progression of the shallow moist air, and a well-defined dryline formed in the morning hours of 22 June 2010 just east of the rim, at the intersection of the shallow moist wedge with the ground. Daytime boundary layer mixing (Schaefer 1974) and synoptic flow then drove the dryline eastward, starting around 2100 UTC, as detailed in Part I. The terrain is important in dryline formation, not just the gentle slope of the Great Plains (e.g., Schaefer 1974), but also, as discussed in Part I, the cresting at the Laramie Range, where terrain-induced diurnal circulations can influence surface convergence on the lee side (Banta 1984, 1986). The flow characteristics on this day exhibit some similarities to such a rather small-scale terrain-induced circulation. Evidence was given in Part I showing that the larger-scale environmental flow east of the Laramie Range (LR) was primarily driven by a developing lee cyclone to the south, suggesting that the effects of a local terrain-induced circulation, if present, would have been relatively small by comparison.

A closer view of the four individual flight legs (Fig. 2) reveals that the strong flight-level $q_{v}$ gradients along the low-level flight legs correspond very well with the locations of the radar fineline evident in the KCYS WSR$88 \mathrm{D} 0.5^{\circ}$ reflectivity scans. The only leg where this relationship was not observed was leg 3 (Fig. 2c) that was flown at a higher level, above the moist boundary layer. Evidence was presented in Part I for the interpretation of the radar fineline as a convergent dryline. The convergent flow and associated shallow ascent lead to a congregation of insects, resulting in a radar echo (Russell and Wilson 1997; Miao and Geerts 2007), but not all radar finelines are drylines, for example, an 


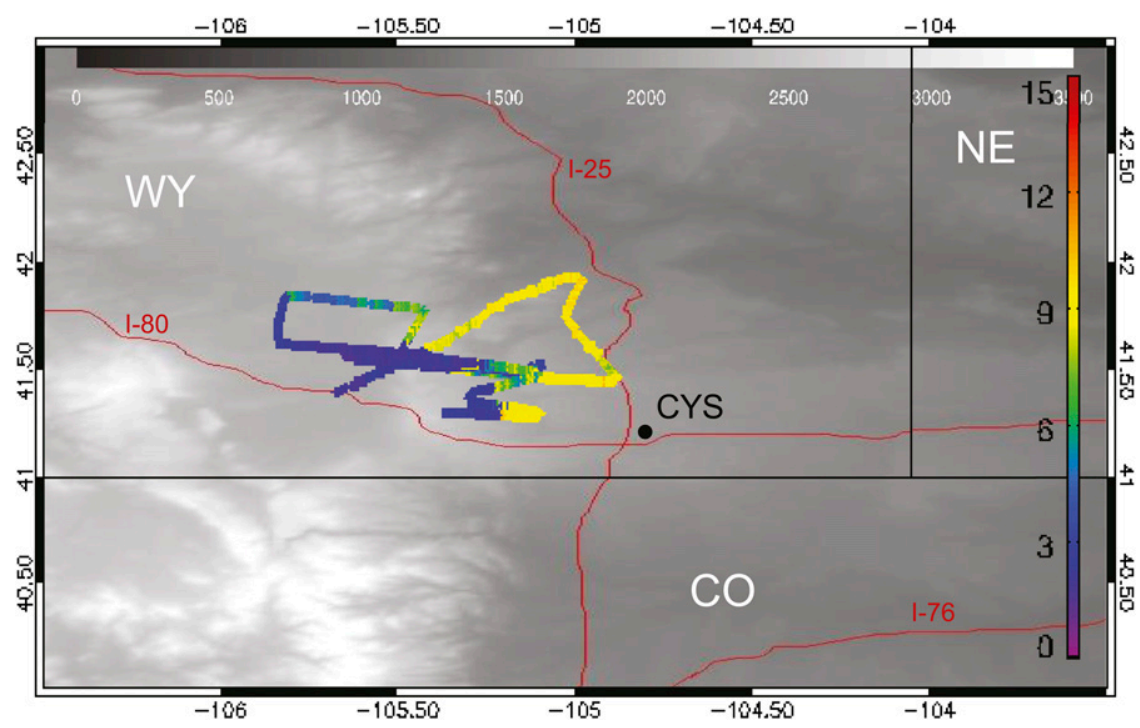

FIG. 1. Map view of the UWKA flight tracks from 2041 to 2210 UTC 22 Jun 2010. The tracks are colored by flight-level $q_{v}$ measurements $\left(\mathrm{g} \mathrm{kg}^{-1}\right)$. The topography is shown in grayscale with the color bar given at the top of the image. The black lines represent state lines, the red lines represent interstate highways, and the black dot shows the location of KCYS (Cheyenne, WY).

outflow boundary is evident in the form of a fineline to the south of the supercell storm in Fig. 2d.

The first flight leg, referred to in this paper as leg 1 (2041-2055 UTC), intersected the moisture boundary approximately $70 \mathrm{~km}$ northwest of KCYS (Fig. 2a). The average altitude of this leg was approximately $500 \mathrm{~m}$ AGL, and its orientation was from southwest to northeast over a distance of about $83 \mathrm{~km}$. The flight-level $q_{v}$ and wind measurements exhibit typical cross-dryline characteristics, with dry $\left(q_{v} \sim 3-5 \mathrm{~g} \mathrm{~kg}^{-1}\right)$ southwesterly flow to the west and moist $\left(q_{v} \sim 9-10 \mathrm{~g} \mathrm{~kg}^{-1}\right)$ southeasterly flow to the east. This corresponds to a $q_{v}$ gradient on the order of around $5 \mathrm{~g} \mathrm{~kg}^{-1}$ over just a few kilometers, similar in magnitude to airborne and ground-based in situ measurements from previous dryline studies (e.g., Ziegler and Hane 1993; Ziegler and Rasmussen 1998; Sipprell and Geerts 2007; Buban et al. 2007). The strong wind shift coincides with the humidity discontinuity. Wind shifts of convergent nature similar to what was observed here are common across drylines, and their strength tends to be related to the strength of the moisture gradient (Rhea 1966; Schultz et al. 2007; Markowski and Richardson 2010, chapter 5.2.2). The thunderstorm that originated south of the flight track around 2015 UTC had moved to the east and developed a V-notch reflectivity pattern typical of a supercell (Fig. 2a).

Leg 2 (Fig. 2b) began about 15 min after the conclusion of leg 1 and extended in a west-northwesterly direction for about $39 \mathrm{~km}$, from 2109 to 2116 UTC. With an average altitude also of approximately $500 \mathrm{~m}$ AGL this leg passed through the moisture boundary approximately $10 \mathrm{~km}$ southeast of leg 1 . Although legs 1 and 2 were flown at about the same altitude and crossed the boundary relatively close to each other in both space and time ( $\sim 30$ min apart), differences in the flight-level $q_{v}$ measurements between the two legs are evident. Thin sections of the leg 2 flight track within the moist boundary layer east of the radar fineline are quite dry, with $q_{v}$ values comparable to those found west of the fineline. It is possible that dry air from aloft was entrained into the shallow moist layer in the wake of its leading edge. This phenomenon has been observed in other dryline studies (Sun and Ogura 1979; Weiss and Bluestein 2002; Weiss et al. 2008). Sometimes the dry air mixes down to the surface, which may explain why moving drylines sometimes appear to discontinuously "jump" to the east during the afternoon (Hane et al. 1993; Crawford and Bluestein 1997). The processes responsible for these drier sections along leg 2 will be explored further in section $3 \mathrm{c}$.

Leg 4 was flown across the moisture boundary farther to the south from 2201 to 2210 UTC (Fig. 2d) over an area fairly close to where the first deep convective cell was seen on radar several hours earlier. Thus, it is possible that the shallow moist air mass sampled along leg 4 was cooled by convective downdrafts, a possibility we will examine in the next section. At 2206 UTC, an outflow boundary marked by a radar fineline appears to be present in Fig. $2 d$ just north of KCYS, extending 


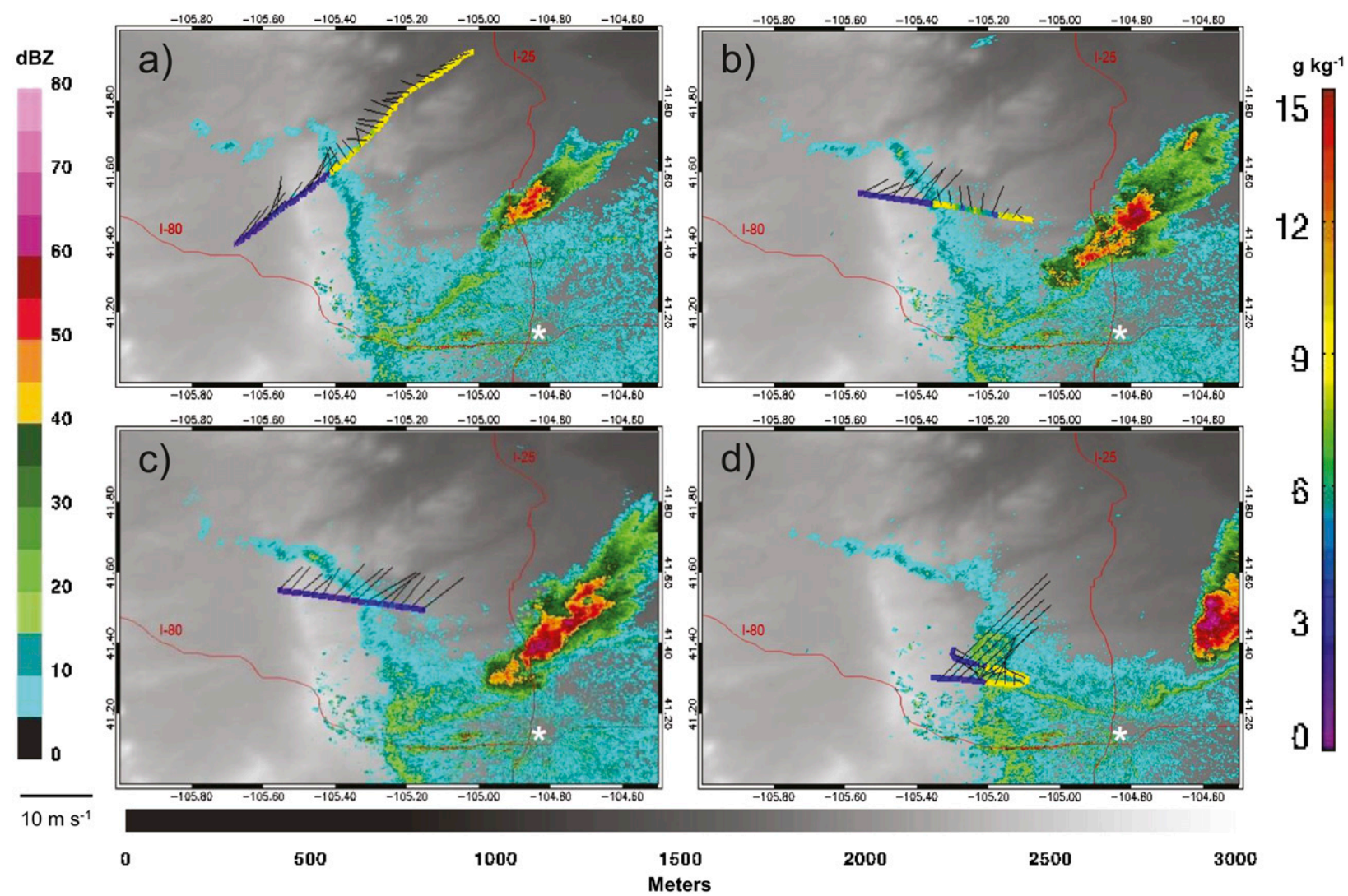

FIG. 2. Flight legs and wind vectors centered over SE WY for (a) leg 1, 2041-2055 UTC; (b) leg 2, 2109-2116 UTC; (c) leg 3, 21202125 UTC; and (d) leg 4, 2201-2210 UTC. The topography is shown in the same manner as in Fig. 1, and the flight legs are once again colored by flight-level $q_{v}$ measurements. Wind vectors are shown as lines with origin on the flight leg (i.e., banners pointing downwind), in length proportional to the wind speed $\left(10 \mathrm{~m} \mathrm{~s}^{-1}\right.$ vector shown at bottom left for reference). All flight legs were flown at $\sim 500 \mathrm{~m}$ AGL (2300-3000 m MSL), with the exception of (c), which was flown at $\sim 1500 \mathrm{~m}$ AGL ( $\sim 3600 \mathrm{~m}$ MSL). Base reflectivity from the Cheyenne WSR-88D (KCYS, located at the white asterisk) is shown at the closest scan times to when the aircraft flew through or over the strongest humidity gradient. These times are 2043, 2110, 2124, and 2206 UTC for (a)-(d), respectively.

westward and intersecting the dryline fineline below the leg 4 flight track. This flight track consists of two separate legs, both of them intersecting a well-defined moisture boundary at a flight level of approximately $500 \mathrm{~m}$ AGL. The boundary here was marked by a $q_{v}$ jump and wind shift.

Finally, leg 3 (Fig. 2c) differed significantly from the other three, which is why it is discussed last. Flown along the same track as leg 2 but at a higher altitude, around $1500 \mathrm{~m}$ AGL, leg 3 (2120-2125 UTC) primarily sampled the dry, potentially warm air of the residual mixed layer above the shallow moist boundary layer. This air mass is part of the deep, dry convective boundary layer over the higher terrain to the west. This air mass became elevated when transported above the shallow moist boundary layer to the east by strong southwesterly flow. This flow actually intensifies as the boundary layer becomes residual (see wind vectors in Fig. 2c), presumably because of decoupling from the surface friction east of the moisture boundary. While the air generally is dry along leg $3\left(q_{v}<5 \mathrm{~g} \mathrm{~kg}^{-1}\right)$, there are several small local maxima $\left(q_{v} \sim 5 \mathrm{~g} \mathrm{~kg}^{-1}\right)$ at and just east of the radar fineline. An analysis of the vertical moisture profile along this leg, given in section 3c, will show that these local maxima are actually important for understanding how convection may have initiated earlier in the day.

\section{b. Saturation point analysis}

To determine if and where the dryline may have been modified by convective outflow during the UWKA flight, we present a saturation point analysis (Betts 1982) for three of the flight legs and for KCYS Automated Surface Observing System (ASOS) data (Fig. 3). Leg 3 is excluded as the UWKA did not sample in situ data within the moist layer. In this analysis, LCLs ("saturation points") are computed using flight-level temperature and humidity data from flight segments on both sides of the moisture boundary (within $2.5-7.5 \mathrm{~km}$ ) and then plotted on a skew 
a) Leg 1

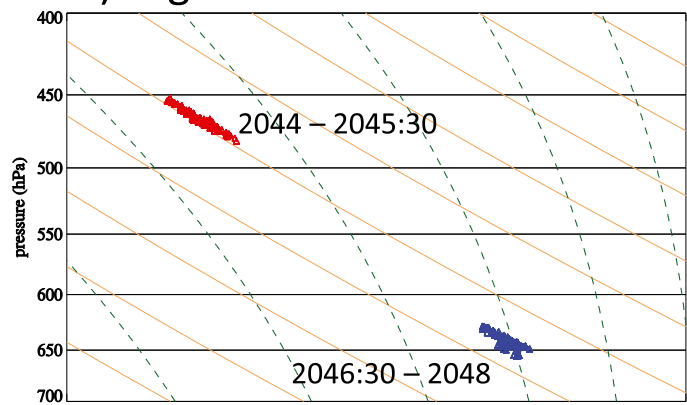

c) Leg 4

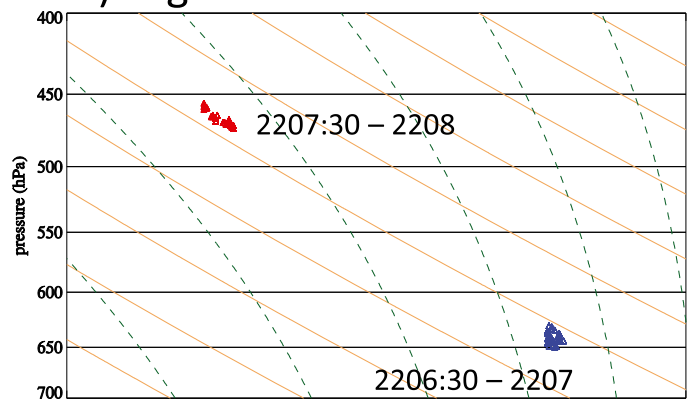

b) Leg 2

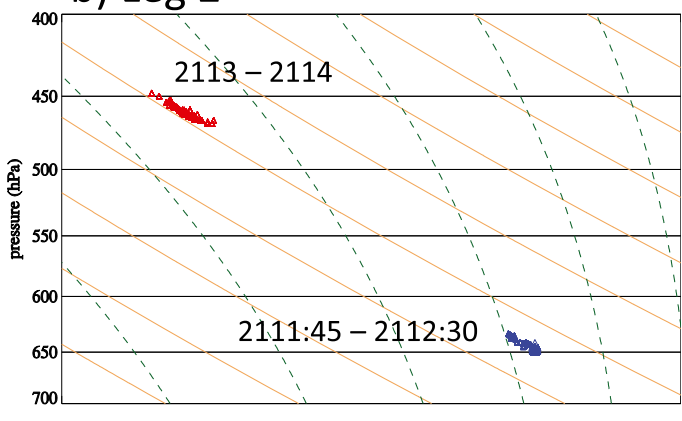

d) KCYS (1800-2210 UTC)

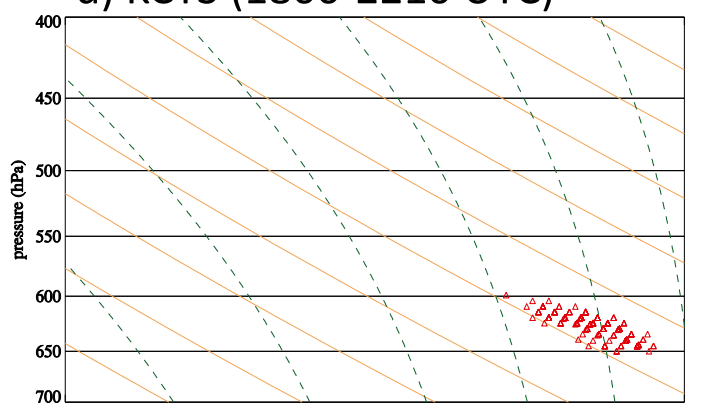

FIG. 3. Saturation point analysis (Betts 1982) for (a) leg 1, (b) leg 2, (c) leg 4, and (d) 1800-2210 UTC surface observations from the KCYS ASOS. The analysis for the three legs uses UWKA in situ temperature and dewpoint data to find the LCL. Points west (east) of the dryline are given in red (blue), and the corresponding flight segment times are UTC. The elevation of the KCYS ASOS is $\sim 1860 \mathrm{~m}$ MSL, while the three legs were all flown at 2300 $3000 \mathrm{~m}$ MSL.

$T-\log p$ diagram. A distribution of saturation points falling along a dry virtual adiabat implies that a well-mixed convective boundary layer is sampled, where surface heat fluxes create variations in temperature and humidity, but buoyancy $\left(\theta_{v}^{\prime}\right)$ variations are removed quickly by convective motions. Saturation points falling along a moist virtual adiabat suggest that the air parcels were evaporatively cooled to different degrees, for example, because of the different proximities to a convective rain shaft. In that case, the boundary is likely to originate from a thunderstorm outflow. Similar analyses have been presented in Ziegler and Hane (1993) and Geerts (2008).

Saturation points on the west side of the moisture boundary within the dry convective boundary layer along legs 1, 2, and 4 (Figs. 3a-c, red triangles) lie approximately along the same dry virtual adiabat, as expected. East of the moisture boundary (blue triangles) the saturation points are significantly cooler and lower, although they still appear to lie along dry adiabats for legs 1 and 2. A handful of these eastern saturation points in leg 1 (Fig. 3a) appear to deviate from the prevailing cluster and are perhaps oriented along a secondary moist virtual adiabat, suggesting the possible presence or influence of rain-cooled air along some eastern portion of the leg. Thus, it appears that these two legs indeed intersected a dryline and not outflow-cooled air, at least at flight level. The distribution of saturation points east of the boundary along leg 4 is more difficult to discern, possibly because the sample size is relatively small ( $\sim 30$ over a distance of $3 \mathrm{~km}$ ). However, a convective outflow boundary from an earlier thunderstorm (seen intersecting the dryline fineline in Fig. 2d) may have modified the air just east of the dryline along this leg. Farther south, the saturation point distribution of 1-min KCYS ASOS data from 1800 to 2210 UTC (Fig. 3d) approximates a dry virtual adiabat, supporting the implication from Fig. $2 d$ that the outflow boundary had not yet reached KCYS while the UWKA was completing leg 4. This analysis supports the hypothesis that the moisture boundary transected locally by the UWKA was indeed the dryline evident in larger-scale analyses presented in Part I.

\section{c. Dryline vertical transects}

To our knowledge only one airborne lidar vertical water vapor transect across a dryline has been documented in the literature (Wakimoto et al. 2006). That study used the Lidar Atmospheric Sensing Experiment (LASE) differential absorption lidar, with a horizontal (vertical) resolution of $14 \mathrm{~km}(330 \mathrm{~m})$, that is, more than 

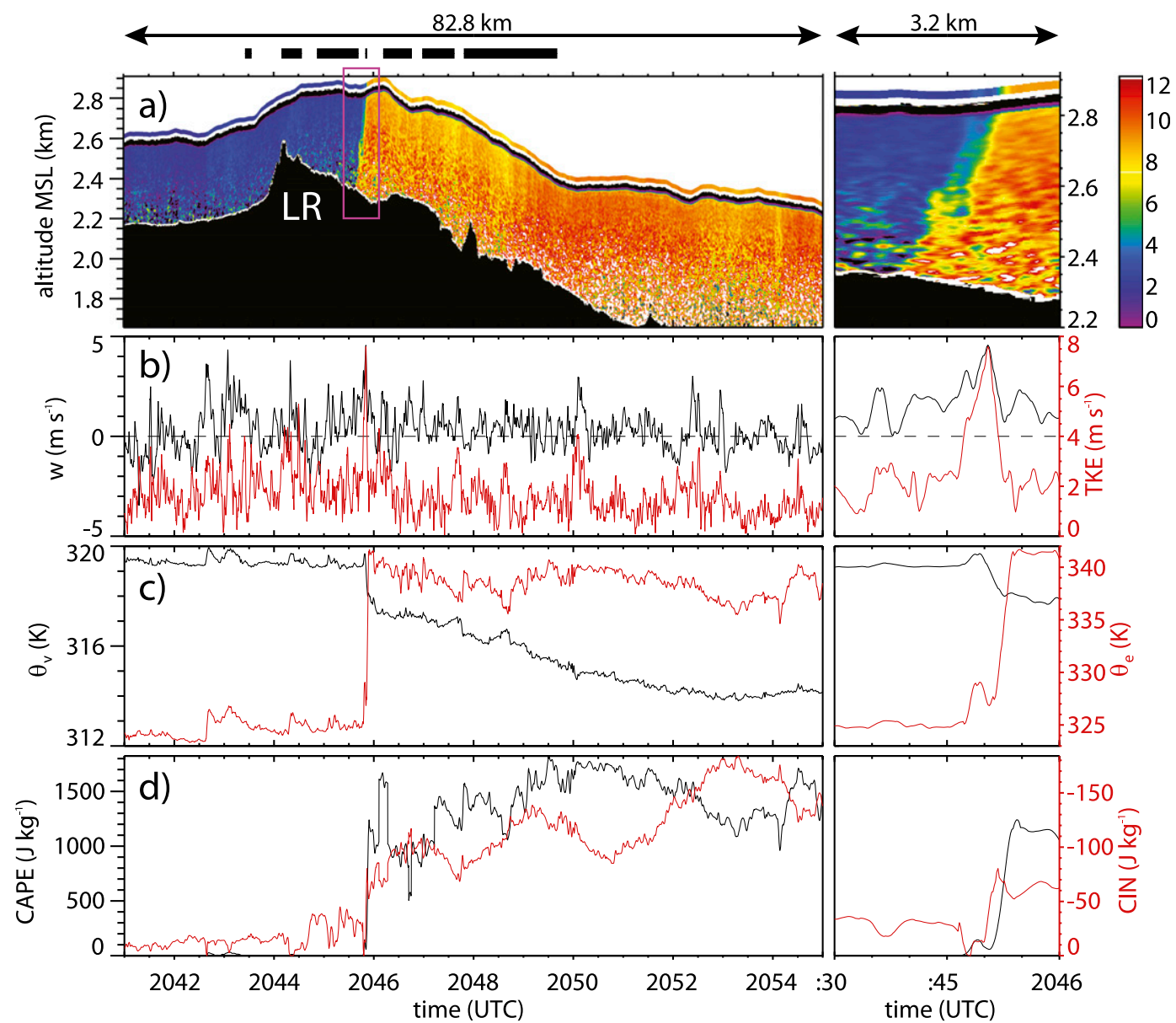

FIG. 4. Raman lidar and UWKA flight-level data for leg 1 (shown in Fig. 2a) from 2041 UTC at left (southwest) to 2055 UTC at right (northeast) across the LR for (a) vertical transect of Raman lidar $q_{v}\left(\mathrm{~g} \mathrm{~kg}^{-1}\right)$ below flight level. The terrain is evident as the black-filled region below, while the black line near the top represents the UWKA flight level. The colored line above the black line represents the flight-level $q_{v}$ measurements, that is, the same data shown in Fig. 2. The flight segments where the UWKA flew below relatively low-based clouds, as suggested by the flight-level radiation criteria, are shown by the thin black bars above (a). (b) Flight-level TKE and $w$, (c) flight-level $\theta_{v}$ and $\theta_{e}$, and (d) CAPE and CIN calculated from WRF soundings modified by UWKA flight-level temperature and dewpoint. (right) The smaller panels of (a)-(d) are close ups of the dryline interface, covering 30 s of flight time from 2045:30 to 2046:00 UTC. The lidar close-up panel at the top right is of the region within the magenta box in the right-hand of (a).

one order of magnitude coarser than the Raman lidar used in this study. Here we analyze Raman lidar vertical transects of the dryline together with relevant flightlevel thermodynamic and wind data for all four flight legs shown in Fig. 2. As before, we will examine the three low-level legs (Figs. 4, 5, 7) first and leave leg 3 (Fig. 6) for the next section.

The Raman lidar vertical profiles of $q_{v}$ (converted from lidar-measured water vapor mixing ratio) for legs 1, 2, and 4 (Figs. 4a, 5a, and 7a, respectively) reveal the dryline as a distinct, sharp moisture boundary, with as much as a $6-8 \mathrm{~g} \mathrm{~kg}^{-1}$ difference in $q_{v}$ over just a few kilometers. In each of the four transects (including the twin transects for leg 4), the boundary appears upright, but actually tilts toward the moist air mass. This suggests that the moist air mass is also denser: baroclinic boundaries tilt toward the cold air. The slope $(\delta z / \delta x)$ (i.e., "elevation angle") of the boundary appears steep because of the height exaggeration in the plot, but it ranges between just $20^{\circ}$ and $40^{\circ}$ from the horizontal, for the four transects available. This can be seen more easily in the zoomed-in "close-up" panels to the right of Figs. $4 \mathrm{a}, 5 \mathrm{a}$, and $7 \mathrm{a}$, where the horizontal distances are shorter and the aspect ratios of the plots are about $4: 1$ on average [these close-up panels are hereby considered part of panels (a)-(d) in Figs. 4-7]. This slope is shallower than the average slope of the leading edge of a cold-frontal density current measured at comparable resolution in 


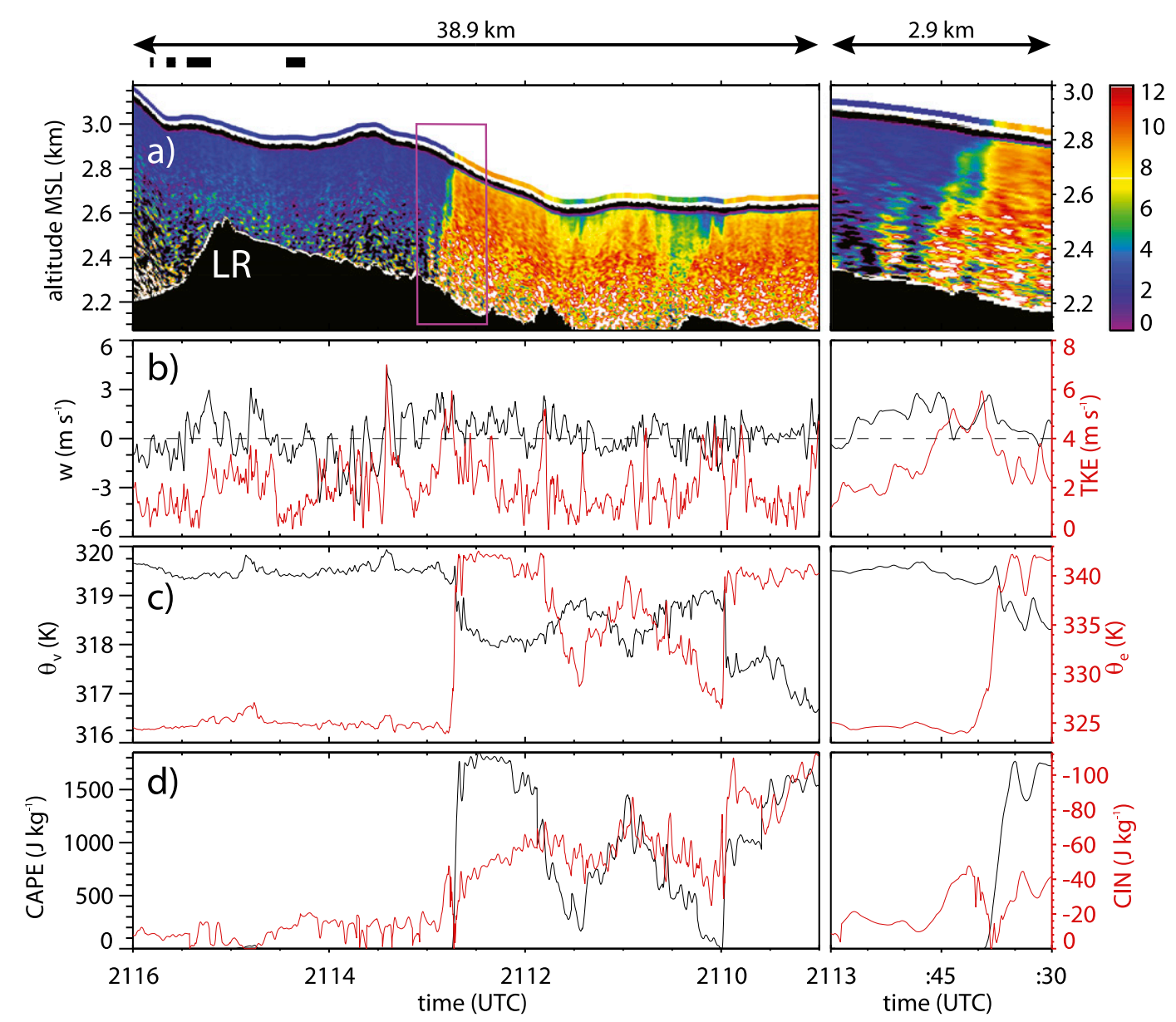

FIG. 5. As in Fig. 4, but for leg 2 (shown in Fig. 2b) between 2116 UTC at left (west) and 2109 UTC at right (east).

2002 (Geerts et al. 2006), but the sample size was equally small and the variability from one transect to the next equally large. The relatively shallow slope may be the result of the strong southwesterly (cross boundary) vertical shear across the moist-air wedge.

The close-range Raman lidar $q_{v}$ variations correspond very well with those measured at flight level (the lidar blind zone is $30-50 \mathrm{~m}$ ). The vertical structure of the dryline in Fig. 4a is similar to findings from other observational studies (Ziegler and Hane 1993; Hane et al. 1993; Atkins et al. 1998; Demoz et al. 2006; Miao and Geerts 2007; Weiss et al. 2008). The vertical velocity ( $w$ ) and turbulent kinetic energy (TKE) measurements from the UWKA (Fig. 4b) indicate that both the dry and moist sides of the low-level flight legs were within the turbulent convective boundary layer. The vertical velocity fluctuations and TKE tend to be larger on the dry side where the well-mixed boundary layer is deeper.

A sharp drop in virtual potential temperature $\left(\delta \theta_{v} \sim\right.$ $1.5 \mathrm{~K}$ ) from west to east immediately across the dryline was observed in each of the penetrations (Figs. 4c, 5c, and $7 \mathrm{c}$ ). Similar cross-dryline $\theta_{v}$ differences have been noted in previous studies (Ziegler and Hane 1993; Atkins et al. 1998; Sipprell and Geerts 2007; Miao and Geerts 2007). This sudden drop and the continued cooling behind the leading edge, most obvious in leg 1 that penetrated the moist layer farthest to the east (Fig. 4c), confirm that drylines frequently exhibit behavior consistent with density current theory (Geerts 2008). The $\theta_{v}$ differences indicate that the moist air mass was about $1 \%$ denser on average than the dry air mass for these legs $(\sim 1.7 \%$ denser for leg 1$)$. Yet solenoidal overturning across the boundary is difficult to discern in the flight-level $w$ field, which is dominated by convective vertical motions, also consistent with previous dryline observations (Sipprell and Geerts 2007; Miao and Geerts 2007).

The convective potential can be determined from the equivalent potential temperature $\left(\theta_{e}\right)$ profile in Fig. $4 \mathrm{c}$ and the CAPE and CIN profiles in Fig. 4d. CAPE 

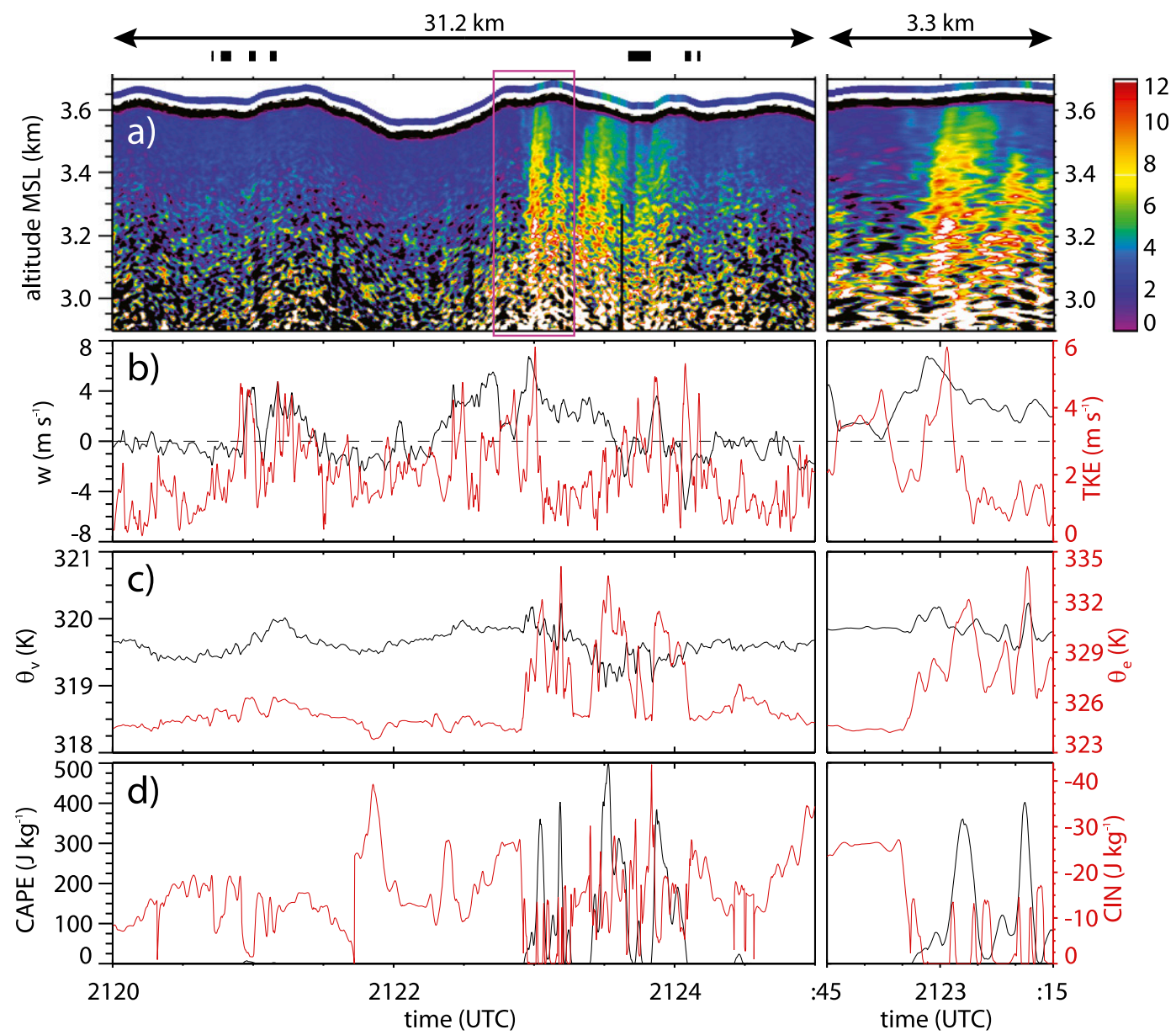

FIG. 6. As in Fig. 4, but for leg 3 (shown in Fig. 2c) between 2120 UTC at left (west) and 2125 UTC at right (east). The terrain is not visible in (a) since the flight level is $\sim 1500 \mathrm{~m}$ AGL.

and CIN were calculated at each point along the flight leg using an adjusted sounding based on flight-level measurements. The soundings were derived from the 1-km WRF output discussed in Part I, using spatially weighted averages from grid points within $2 \mathrm{~km}$ of the actual UWKA locations. No radiosonde data, representative of the unstable air mass east of the dryline, were available. [The closest National Weather Service sounding was from Denver, Colorado (KDNR), $\sim 150 \mathrm{~km}$ to the south and in the dry air mass by 0000 UTC 23 June.] But the WRF simulation nicely captures the location and intensity of the dryline, as will be discussed later; thus, the model free-tropospheric temperature profiles are likely to be representative above flight level. The model soundings were then modified with $\theta_{v}$ and $q_{v}$ at flight level, which was considered the source level for the CAPE and CIN calculations. Since the UWKA was flying within the well-mixed convective boundary layer (either dry or moist), according to the TKE and $w$ traces, the resulting CAPE (and CIN) represent mixed-layer values, equivalent to the mixed-layer CAPE (CIN) computed from surfacebased soundings. This applies to all flight legs, except to the eastern portion of leg 3 , which was above the moist boundary layer.

No CAPE is present on the dry side, and CAPE values $>1500 \mathrm{~J} \mathrm{~kg}^{-1}$ are found in the moist boundary layer east of the dryline in all three transects. Substantial CIN is present to the east, as absolute values exceed $100 \mathrm{~J} \mathrm{~kg}^{-1}$ there (Figs. 4d, 5d). Slightly higher values of CAPE $\left(\sim 1800 \mathrm{~J} \mathrm{~kg}^{-1}\right)$ are found closer to the dryline along leg 1 (Fig. 4d), with similar or greater values seen near the dryline for the other two penetrations (Figs. 5d, 7d). A local minimum in CIN $\left(|\mathrm{CIN}|<50 \mathrm{~J} \mathrm{~kg}^{-1}\right)$ was also observed here in legs 1 and 2 (Figs. 4d and 5d), and in leg 4 CIN approached zero with CAPE of about $2000 \mathrm{~J} \mathrm{~kg}^{-1}$ within a few kilometers east of the dryline in both penetrations (Fig. 7d). This suggests the presence of unstable parcels of air capable of producing deep convection if they were able to attain their LFC. 


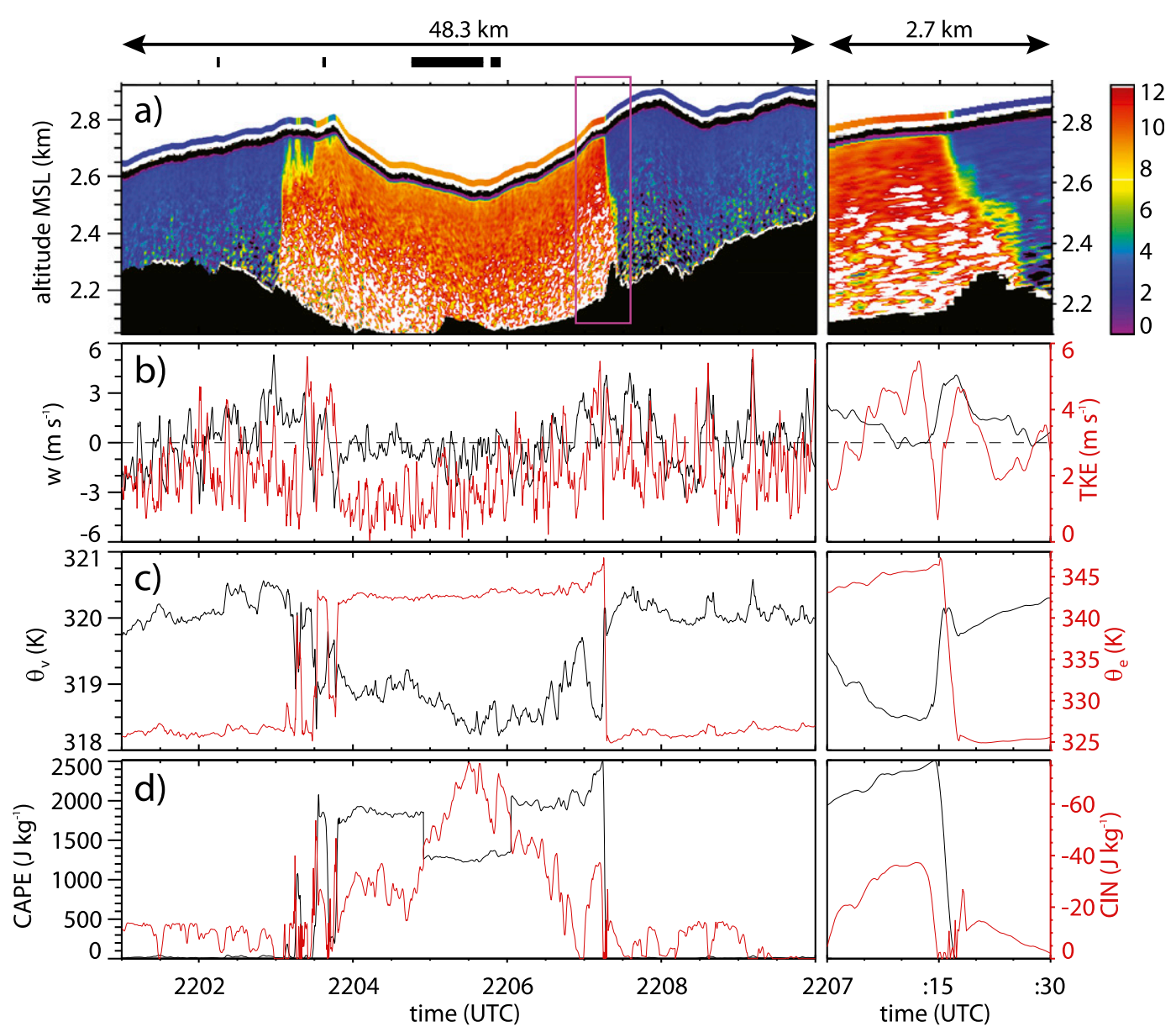

FIG. 7. As in Fig. 4, but for leg 4 (shown in Fig. 2d; 2201-2210 UTC). For this leg the UWKA begins flying from west to east, turns around near 2205 UTC, and ends flying from east to west.

\section{d. Cumulus formation along the dryline}

Although the UWKA did not fly through or below any deep convection during leg 1 (see Fig. 2a), it did fly across a clear section of a broken line of shallow cumulus that was oriented north-to-south along the dryline at this time (Fig. 8a). This was confirmed by photographs taken aboard the aircraft (not shown). The presence of cumulus clouds overhead the UWKA is estimated through a simple algorithm that utilized in situ visible and infrared radiation measurements from a pyranometer and a pyrgeometer on top of the aircraft. Overhead cumulus along the flight track was determined to be likely where visible (shortwave) radiation was greatly diminished (by at least $50 \%$ ) from its clear-sky value and where the downwelling infrared (longwave) radiation was enhanced to a value representative of what one would expect from an overhead cloud with cloud-base temperature approaching the LCL temperature. That value was found by incorporating the flight-level LCL temperature into the Stefan-Boltzmann equation, assuming a cloud emissivity of 0.98 . The maximum downwelling IR radiation was used below any cloud, because the radiation sensor is hemispheric. The cloud edges were then determined using the cloud shadow edges from the pyranometer. Flight segments where these criteria were met are shown by the thick, black bars above panel (a) in Figs. 4-7. The spacing of the overhead cumulus near the dryline is consistent with a photogrammetric analysis carried out in Ziegler and Rasmussen (1998). This procedure does not yield cloud-base height, especially for the smaller clouds.

According to this estimation method, cumulus clouds were present near the dryline (within $\sim 10 \mathrm{~km}$ ) along leg 1 , mostly but not only on the moist side (Fig. 4). The high $q_{v}$ values near the dryline indicate that the moist boundary layer had deepened substantially at this point, likely a result of moisture convergence and plumes of locally higher $q_{v}$ rising from near the surface to the flight level and beyond. In short, flight-level data indicate that CAPE peaked and CIN was at a minimum close to the dryline. 


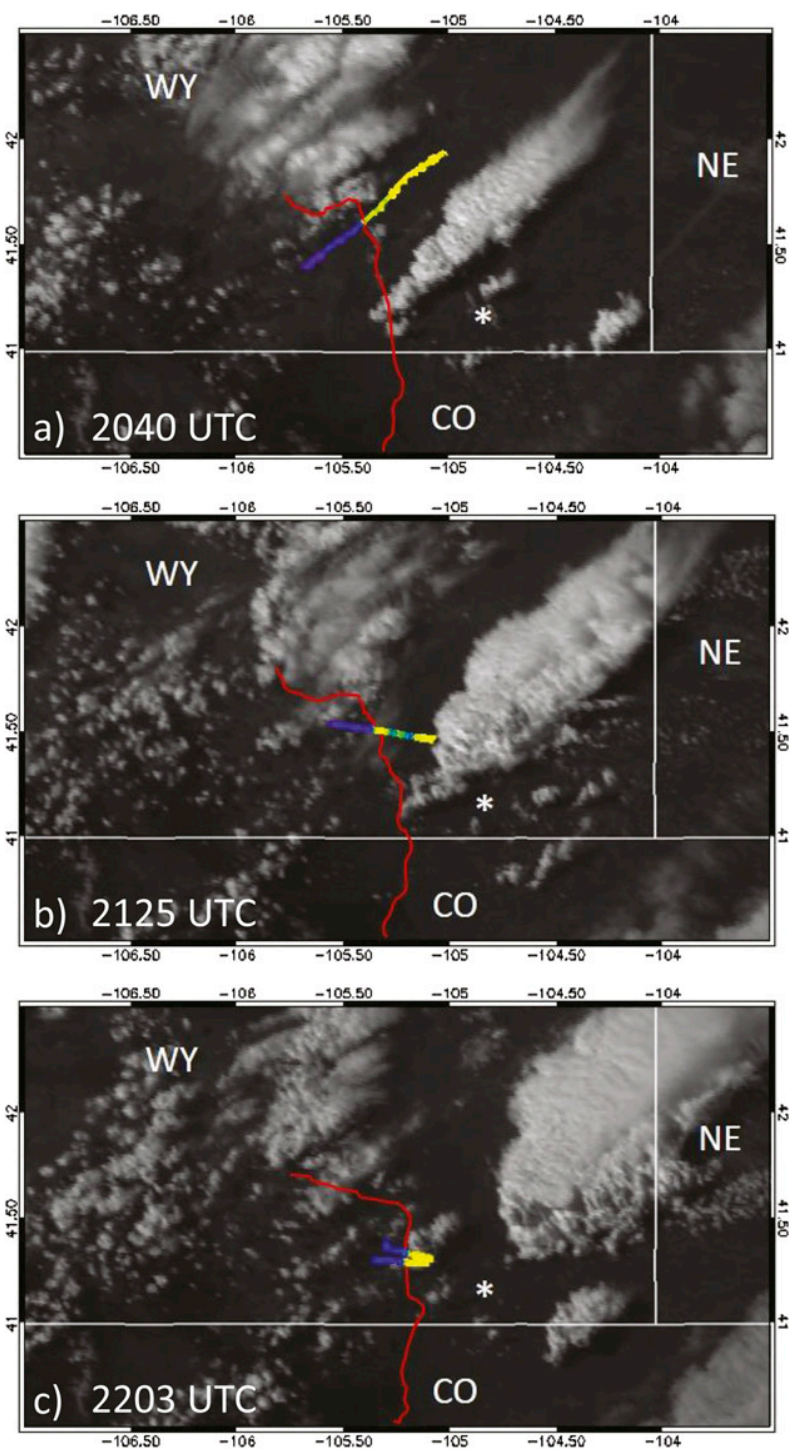

FIG. 8. GOES-13 visible satellite image on 22 Jun 2010 for (a) leg 1 , (b) leg 2, and (c) leg 4 . The images were selected based on their temporal proximity to the flight legs. The red line in each image corresponds to the location of the KCYS WSR-88D fineline at the time the UWKA intersected the dryline (see Fig. 2). The white asterisk shows the location of KCYS. State lines and names are in white. The flight tracks of each leg are colored in the same manner as in Fig. 1.

The Raman lidar data reveal two distinct protrusions of drier air between 2110 and 2112 UTC along leg 2 (Fig. 5a). In the first case (just after 2110 UTC), the drier air appears to have penetrated downward several hundred meters into the moist layer. These protrusions were associated with locally higher $\theta_{v}$ and lower $\theta_{e}$ (Fig. 5c), both approaching values typical of the west side of the dryline, along with CAPE values approaching zero (Fig. 5d). Weak subsidence prevailed in these protrusions in a turbulent environment (Fig. 5b), perhaps a reason for why the air above appears to have been cloud free (Fig. 8b; onboard photographs). These protrusions were also associated with bursts of southwesterly wind (Fig. 2b). The implication is that the protruding air likely originated within the dry convective boundary layer west of the dryline and was then transported downward into the moist layer through strong vertical mixing, possibly associated with Kelvin-Helmholtz billows, which are common along density currents in sheared flow (e.g., Xue et al. 1997; Xue 2002; Geerts et al. 2006). No cumulus clouds were present along leg 2 according to flight-level downwelling visible and IR radiation measurements (black bar above Fig. 5a), consistent with GOES-13 visible satellite imagery (Fig. 8b).

A cumulus cloud was evident approximately $10 \mathrm{~km}$ east of the dryline above leg 4 from examination of the 2203 UTC GOES-13 image (Fig. 8c) and from the black bars above Fig. 7a (2205-2206 UTC). With CAPE approaching $2500 \mathrm{~J} \mathrm{~kg}^{-1}$ and CIN close to zero near the dryline (Fig. 7d), any rising parcels within these clouds able to survive entrainment in the drier air above the moist boundary layer and attain their LFC would have likely led to deep convection similar to what was observed earlier in the day. Deep convection did indeed emerge from this cloud east of the dryline, or another cumulus just to the north (Fig. 8c), following the completion of leg 4 around 2240 UTC (see Fig. 7b in Part I). Note that small, high-base cumulus clouds also developed over the Rocky Mountains west of the dryline (Fig. 8). These advected to the northeast but produced very little or no precipitation at the surface (Fig. 2).

Clues as to how these rising parcels may have survived entrainment are uncovered by analyzing the lidar data from leg 3 (Fig. 6a). The reader is reminded that leg 3 was flown above the moist boundary layer at an altitude of around $1500 \mathrm{~m}$ AGL. Several vertical plumes of $q_{v}>$ $10 \mathrm{~g} \mathrm{~kg}^{-1}$ were measured between 2123 and 2124 UTC. These plumes were located just east of the WSR-88D fineline at this time (Fig. 2c), that is, above the moist layer east of the dryline. Vertical velocities were far more coherent and highly positive near the plumes, with peak values around $6 \mathrm{~m} \mathrm{~s}^{-1}$ (Fig. 6b). The plumes were enriched with boundary layer air, given the higher $\theta_{e}$ (Figs. 6c-d) in an environment that is potentially unstable $\left(\partial \theta_{e} / \partial z<0\right)$, according to WRF output (not shown). Thus, these plumes are interpreted as moist updrafts penetrating into the free atmosphere east of the dryline from the moist boundary layer below. In other words, the plumes seem to represent a deepening of the moist boundary layer at this location. The air within the plumes was not remarkably buoyant at this level, as the ascent was dry adiabatic, still well below cloud base, according to the sounding. The cloud criteria (black bars 
above Fig. 6a) indicate that a cloud may have been present above the UWKA between 2123:30 and 2140:00 UTC on the eastern side of the plumes. The identification of cumulus overhead was more uncertain however for leg 3 , given that the flight-level air mass (and thus LCL) was not representative of the source air mass of any cumuli overhead. Higher clouds (i.e., clouds advected eastward from west of the dryline) may have been present from the examination of onboard photographs (not shown). The implications of the plumes and their impact on CI will be explored in section $3 \mathrm{e}$.

\section{e. WRF comparison}

In Part I, 1-km WRF output was used to deduce the presence of HCRs and small-scale cyclonic vortices near the dryline. It was concluded that these features likely played a role in the initiation of convection, at least within the model. In this paper, the same 1-km WRF output is compared with the lidar and flight-level data obtained in leg 1 to examine how well the model simulated the vertical structure of the dryline. Because the model dryline exhibited an excessive eastward bulge across this region and was generally located several tens of kilometers east of the observed dryline (see Part I for details), it ended up being east of the locations of legs 2 , 3 , and 4 . At the location and time of leg 1 , however, the model dryline was only about $10 \mathrm{~km}$ to the east of the observed dryline. Thus, the model vertical structure of the dryline could only be validated along leg 1 (Fig. 9).

A model cross section along leg 1 at 2100 UTC (near the time of leg 1) shows the vertical distribution of several variables including $q_{v}$ (Fig. 10a). The red line in the cross section represents the UWKA flight level. This cross section, whose location is shown as the straight red line in Fig. 9, intersects simulated convective activity east of the model dryline (blue line in Fig. 9), leading to the possibility that the modeled moist boundary layer in the far eastern sector of this transect may have been cooled by deep convection. Comparisons can be drawn between the model cross section (Fig. 10a) and the lidar profile from Fig. 4a. First, the dryline boundary revealed by the strongest horizontal $q_{v}$ gradient is well defined in both figures. The model cross section, however, shows the entire moisture profile up to $600 \mathrm{hPa}$, while the lidar data were limited to the lowest $\sim 500 \mathrm{~m}$ AGL. Additionally, the strength of the observed moisture gradient was much stronger than that of the model, likely because the horizontal resolution of the lidar data was greater than that of the model. It also appears that the model was slightly drier in general with $q_{v}$ values topping out at 8$9 \mathrm{~g} \mathrm{~kg}^{-1}$ compared to $>10 \mathrm{~g} \mathrm{~kg}^{-1}$ as measured by the lidar.

A comparison of model data (black lines) and observed flight-level data (red lines) for leg 1 is shown in

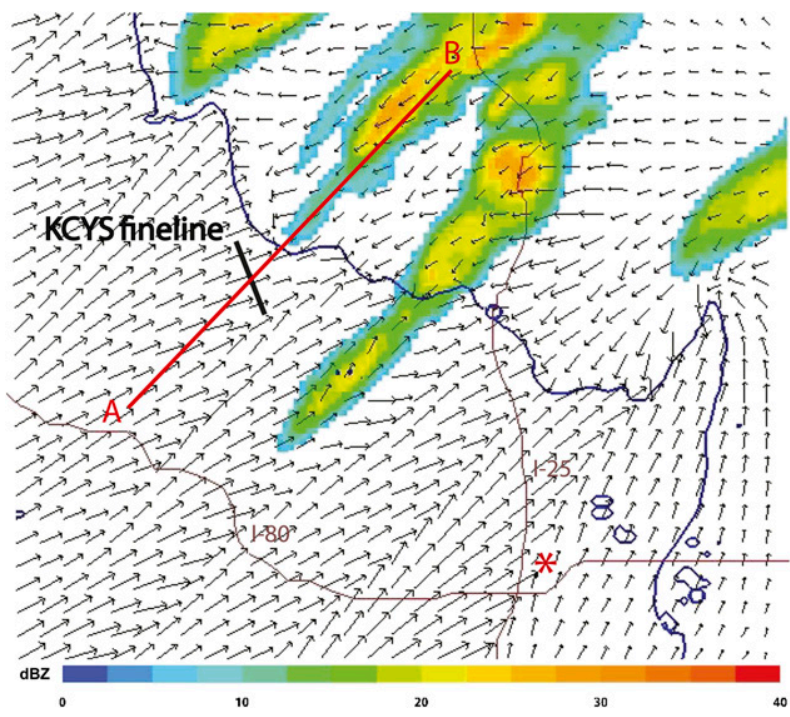

FIG. 9. Model 10-m horizontal wind vectors and composite reflectivity (dBZ; color scale at the bottom) at 2100 UTC 22 Jun 2010. Also shown in blue is the $5 \mathrm{~g} \mathrm{~kg}^{-1} 2-\mathrm{m} q_{v}$ contour that is located along the strongest $q_{v}$ gradient (i.e., the modeled dryline; see Part I). The thick red line approximately represents the leg 1 flight track. The thick black line across the flight track corresponds to where the UWKA crossed the KCYS WSR-88D fineline at 2043 UTC. The red asterisk shows the location of KCYS, and the thin black lines are interstate highways.

Figs. 10b-f. Data were extracted from the same model soundings used to compute CAPE and CIN and vertically interpolated to the pressure levels of the UWKA flight track (red line in Fig. 10a). In other words, the model variables shown in Figs. 10b-f are the model representations of the leg 1 in situ flight-level data. The dryline location itself, revealed by the sharp decrease (increase) in $\theta_{v}\left(\theta_{e}, \mathrm{CAPE}\right.$, and CIN), is displaced farther to the east in the model by about 1-2 min of UWKA flight time. This corresponds to a distance of about 5$10 \mathrm{~km}$, consistent with what was shown in Fig. 9. Aside from this difference, the model profiles appear to match up fairly well with UWKA observations, at least qualitatively, especially west of the dryline. East of the dryline, the model profiles of $\theta_{v}$ are typically within $1-2 \mathrm{~K}$ of the observed values (Fig. 10c). The magnitudes of model $\theta_{e}$ and CAPE (Figs. 10d,e) near the dryline do not increase as sharply as the observations but do approach the observed values farther east. Maximum model CAPE approaches $1200 \mathrm{~J} \mathrm{~kg}^{-1}$, about $600 \mathrm{~J} \mathrm{~kg}^{-1}$ less than observed. The profiles of model and observed CIN (Fig. 10f) seem to show the most agreement of all the variables. The cross-sectional analysis of Fig. 10a and the good correspondence between model and observations in terms of $\theta_{v}$ also support our interpretation that this dryline behaves as a density current. 

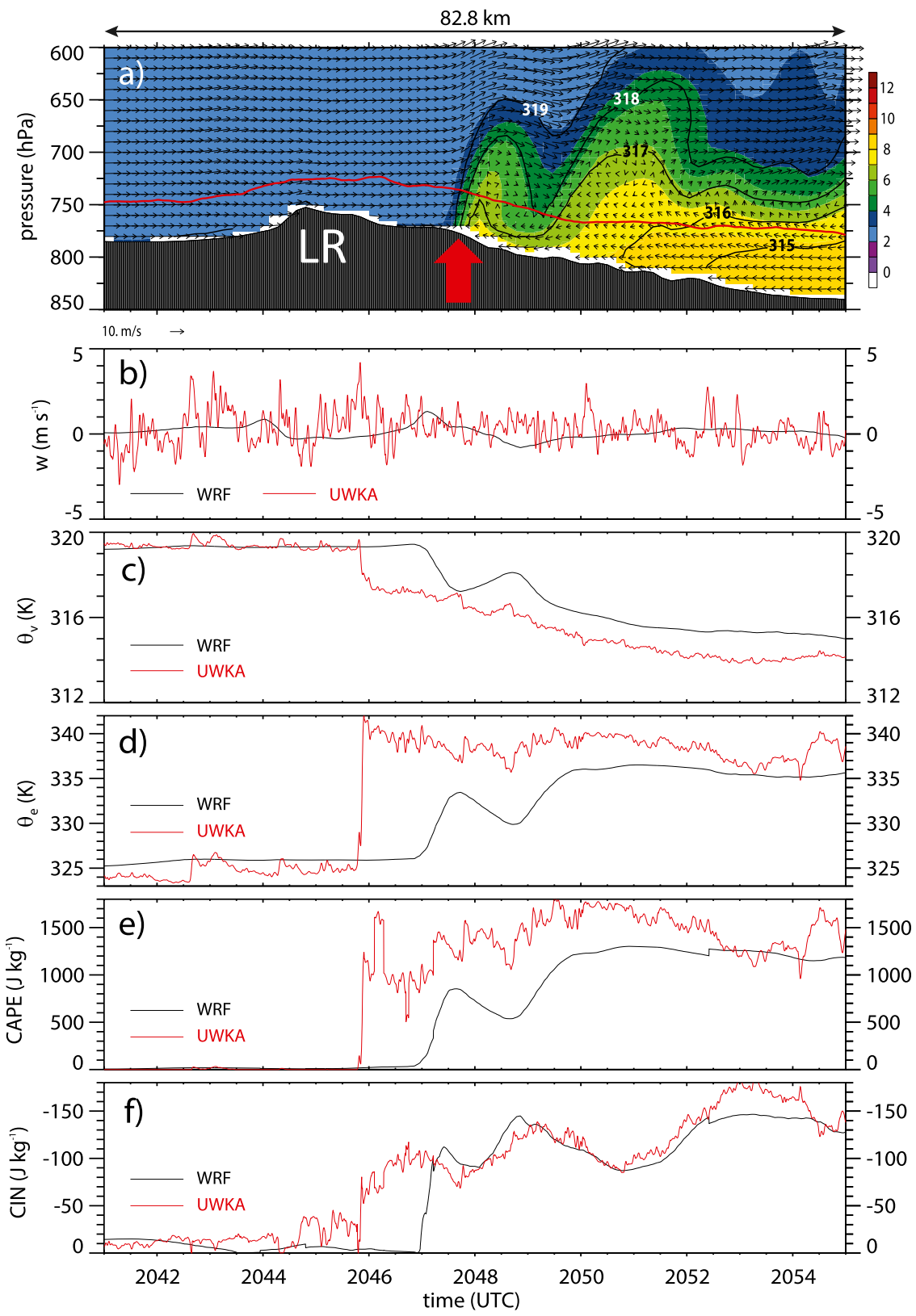

FIG. 10. Plots constructed similar to Fig. 4 except comparing 1-km WRF flight-level output at 2100 UTC to UWKA in situ data. The flight-level model data in these plots were obtained through spatially weighted average soundings from along the leg 1 flight path (from left to right shown by the thick red line in Fig. 9 from point A to B). (a) WRF vertical cross section of $q_{v}$ (color filled), $\theta_{v}$ (black lines), wind vectors parallel to the plane of the cross section (arrows), and UWKA flight-level pressure (red line). The Laramie Range is given by LR, and the location of the dryline is shown by the thick red arrow. The model and UWKA data are plotted together for (b) $w$, (c) $\theta_{v}$, (d) $\theta_{e}$, (e) CAPE, and (f) CIN. In (b)-(f), model data (black lines) are obtained at the pressure levels along the UWKA flight track denoted by the red line in (a) and are therefore model representations of the leg 1 flight-level data.

Regarding air motion, the model $w$ in Fig. 10b is much smoother than in reality as the model does not capture the turbulence seen in Fig. 4b. This is to be expected as this $1-\mathrm{km}$ WRF simulation does not resolve turbulent eddies. The model does resolve the solenoidal circulation across the dryline, however, evident from the positive-to-negative change in $w$ from west to east across the dryline and the circulation vectors (Fig. 10a). These 
vectors clearly exhibit clockwise rotation below $650 \mathrm{hPa}$ at and immediately east of the dryline, very similar to the description of a dryline secondary circulation given in Weiss et al. (2008). There is also a significant dip in $q_{v}$ east of the circulation (around 2049 UTC), where the vertical motion becomes negative. This feature is reminiscent to the humidity dip east of the dryline in leg 2 (Fig. 5a).

\section{f. Convection initiation}

An analysis of Fig. 2 shows that no deep convection was initiated along the dryline over the duration of the UWKA flight. A storm, however, had formed along the dryline just before takeoff, around 2000 UTC, and migrated off to the east by the time the flight legs ensued. As mentioned earlier, deep convective activity also formed following the completion of the flight just northeast of KCYS near a triple point of the dryline and an outflow boundary emanating from the original storm (see Figs. 7b-d in Part I). The fact that several flight legs did fly below or near the convective cumulus east of the dryline was noted in section 3c. The likely presence of a solenoidal circulation has been noted as well and, together with an apparent deepening of the moist boundary layer east of the dryline due to enhanced surface convergence (see Part I), would help explain the deep moisture plumes observed along leg 3 (see Fig. 6a).

Regarding CI, the prospect of parcels from these plumes attaining their LCL (leading to CI) and LFC (leading to deep convection), particularly farther south near the actual site of CI several hours earlier, depends on how much entrainment was taking place. If the LCL and LFC were at heights reached by the plumes, it would infer that little to no entrainment was occurring. If these levels were at heights well above the top of the plumes, the effects of entrainment could have been significant enough to prevent CI. LCLs along leg 3 obtained from the aircraft-modified soundings used to calculate CAPE and CIN were about $2000 \mathrm{~m}$ AGL (not shown), well above flight level and as much as $500 \mathrm{~m}$ above the top of the plumes. It is therefore possible that the moist layer was simply not deep enough to provide parcels with enough protection from entrainment, given that the plumes did not extend all the way to the LCL. This appears to be confirmed by visible satellite imagery at 2125 UTC (Fig. 8b) that shows no low-level cumulus development over the easternmost section of leg 3 where the plumes were observed (the reader is reminded that leg 3 flew approximately along the same track as leg 2, except at a higher altitude). A deeper moist boundary layer, or stronger plumes, would have been required to allow moist parcels free, uninhibited ascent to their LCL and LFC.
The question arises as to whether or not the moist layer was deep enough to allow thermals to reach the LFC farther south in the environment sampled by leg 4 , where aircraft data indicate LCL values near $2000 \mathrm{~m}$ AGL, leading to the initiation of deep convection within the narrow (maybe $5-10 \mathrm{~km}$ wide) window just east of the dryline where CAPE was plentiful and CIN was at a minimum. The presence of at least one cumulus cloud above leg 4 at approximately $10 \mathrm{~km}$ east of the dryline (black bars near 2205 UTC above Fig. 7a) and the development of a weak thunderstorm from this or a nearby cumulus cloud some $15 \mathrm{~min}$ after the completion of leg 4 suggest that the answer is affirmative. Model data resolved a number of moist plumes along the dryline at 2000 UTC ( $\sim 2 \mathrm{~h}$ earlier) just east of leg 4 (see Fig. 11b in Part I). These plumes extended to a depth of about $2 \mathrm{~km}$ AGL, close to the height of the aircraft-modified LCLs, and led to shallow cumulus development at the model dryline. Deep convection was later initiated in the model where these plumes reached depths closer to $3 \mathrm{~km}$. Thus, model data suggest that plumes of a similar nature were responsible for the earlier $\mathrm{CI}$ along this section of the dryline.

\section{Discussion}

While this paper offers no new insights regarding dryline structure, it does (to the authors' knowledge) present only the second documented case of an airborne, downward-pointing lidar being used to sample the vertical distribution of water vapor across a dryline at vertical and horizontal resolutions about one order of magnitude better than the previous study (Wakimoto et al. 2006). Also significant is that the data presented constitute the first ever airborne analysis of a dryline in Wyoming and is one of just a few studies of a dryline over the high plains in close proximity to the Rocky Mountains.

The vertical structure of the moisture field near the dryline compares well with less-resolved transects from previous studies (e.g., Ziegler and Hane 1993; Buban et al. 2007). The 22 June 2010 dryline in SE Wyoming was a sharp moisture discontinuity with $q_{v}$ differences on the order of $5-10 \mathrm{~g} \mathrm{~kg}^{-1}$ throughout the depth of the convective boundary layer. In situ measurements from approximately $500 \mathrm{~m}$ AGL reveal a distinct wind shift (Fig. 2), along-track convergence, updrafts up to about $6 \mathrm{~m} \mathrm{~s}^{-1}$, and a density gradient, with a crossdryline $\theta_{v}$ deficit of around $1.5 \mathrm{~K}$ on the moist side. This solenoidal forcing, also present in the 1-km WRF simulation, led to a circulation that was more evident in the model (Fig. 10) than in aircraft observations (Figs. 2b, 5) because the flow within the boundary layer 
was dominated by turbulent eddies. This circulation is dynamically consistent with surface convergence and upward motion at the dryline. Local deepening of the moist boundary layer within this updraft may have resulted in the moisture plumes seen in Fig. 6. However, the fact that these observed plumes did not extend to the LCL (at least not yet, i.e., no large cumulus cloud had formed overhead), and, more generally, the relative paucity of thunderstorm cells emerging from the dryline vicinity on 22 June 2010 (Figs. 2, 8) seem to suggest that the initiation of deep convection is not trivial.

It is possible that the moisture plumes and associated strong updrafts seen in Fig. 6 were associated with HCR intersections or small-scale cyclonic vortices, which were not actually observed along the dryline in this study, but may have been present given their existence in the 1-km WRF simulation (see Part I). Vertical velocities within the plumes (Fig. 6b) were about the same $\left(5-6 \mathrm{~m} \mathrm{~s}^{-1}\right)$ as those seen at the intersections of the HCRs with the dryline in the model (see Fig. 14 in Part I). There is no observed evidence for the presence of HCRs either since the vertical-plane measurements presented in this paper do not measure the 2D horizontal structure. More observations, including horizontal water vapor lidar transects from multiple altitudes, are needed to adequately sample the near-dryline environment.

\section{Conclusions}

This study sought to describe the finescale vertical structure of a SE Wyoming dryline through the analysis of airborne in situ data obtained by the UWKA and remotely sensed water vapor measurements from a compact Raman lidar aboard the aircraft. The airborne Raman lidar measurements of a dryline are the first of its kind and show the moisture gradient at the dryline in very fine detail. This paper also serves as a follow-up to Part I in that it attempts to better describe the finescale dynamics that led to the localized initiation of convection. The data were obtained across a well-defined dryline in SE Wyoming on the afternoon of 22 June 2010. The key findings are as follows:

- The dryline exhibits characteristics similar to drylines studied in the southern Great Plains, that is, it is a convergent boundary with a sharp humidity gradient and a buoyancy gradient (denser air on the moist side).

- The airborne Raman lidar yields specific humidity transects of unprecedented resolution $(\Delta x \sim 500 \mathrm{~m}$ and $\Delta z \sim 30 \mathrm{~m}$ ) across the dryline, sufficiently fine to reveal dry eddies entraining into the moist layer and moisture plumes emerging above the moist layer.

- High CAPE values occur within a few kilometers of the dryline, and vanishing CIN occurs in at least one of the transects, making the dryline environment conducive to $\mathrm{CI}$.

Four different flight legs were examined by looking primarily at the distribution of water vapor both at flight level and over the $\sim 500-\mathrm{m}$ depth below the aircraft measured by the lidar. Each flight leg was unique in its contribution to the analysis. Leg 1 flew perpendicular to the dryline at an altitude of approximately $500 \mathrm{~m} \mathrm{AGL}$ and directly through a section where the dryline was highly convergent. It resolved a very distinct, sharp moisture discontinuity, a drop in virtual potential temperature on the moist side, and wind shift at the boundary. East of the dryline, leg 2 observed evidence of drier air protruding downward into the moist boundary layer from the dry residual layer above, possibly evidence of Kelvin-Helmholtz billows entraining dry air into the moist layer. Leg 3 revealed the presence of fairly deep, buoyant moisture plumes above the moist boundary layer with vertical velocities peaking at about $6 \mathrm{~m} \mathrm{~s}^{-1}$. Finally, leg 4 sampled a very welldefined section of the dryline with CAPE near $2500 \mathrm{~J} \mathrm{~kg}^{-1}$ and CIN almost absent. This leg also happened to fly below, developing cumulus clouds east of the dryline that would later evolve into weak thunderstorms.

This study lacks observations of the threedimensional wind and moisture fields as well as time continuity to adequately document $\mathrm{CI}$ along the dryline. A more comprehensive field campaign is needed to accomplish this goal. Also, further investigation of drylines in SE Wyoming would be useful, especially to assess the influence of the terrain crest and the interactions between the dryline and terrain-induced circulations. In the meantime, the lead author (Bergmaier) is conducting a climatological study of SE Wyoming drylines to gain more insight into their frequency and relationship to CI.

Acknowledgments. The Raman lidar and KAPEE flights were funded by National Science Foundation under Award AGS-0645644, while the work for this paper was partly funded by NSF Award AGS-0964184. The lead author was also partially supported by a fellowship through the University of Wyoming Science Posse, which was funded by NSF GK-12 Project 084129 . The authors thank Yonggang Wang from the University of Wyoming for help in making the modified CAPE and CIN calculations. Appreciation also goes out to Conrad Ziegler and David Whiteman for their constructive input and suggestions, which greatly improved the manuscript. 


\section{REFERENCES}

Atkins, N. T., R. M. Wakimoto, and C. L. Ziegler, 1998: Observations of the finescale structure of a dryline during VORTEX 95. Mon. Wea. Rev., 126, 525-550, doi:10.1175/1520-0493(1998)126<0525: OOTFSO $>2.0 . \mathrm{CO} ; 2$.

Banta, R. M., 1984: Daytime boundary-layer evolution over mountainous terrain. Part I: Observations of the dry circulations. Mon. Wea. Rev., 112, 340-356, doi:10.1175/ 1520-0493(1984)112<0340:DBLEOM >2.0.CO;2.

_ 1986: Daytime boundary layer evolution over mountainous terrain. Part II: Numerical studies of upslope flow duration. Mon. Wea. Rev., 114, 1112-1130, doi:10.1175/1520-0493(1986)114<1112: DBLEOM $>2.0 . \mathrm{CO} ; 2$.

Betts, A. K., 1982: Saturation point analysis of moist convective overturning. J. Atmos. Sci., 39, 1484-1505, doi:10.1175/ 1520-0469(1982)039<1484:SPAOMC >2.0.CO;2.

Buban, M. S., C. L. Ziegler, E. N. Rasmussen, and Y. P. Richardson, 2007: The dryline on 22 May 2002 during IHOP: Ground-radar and in situ data analyses of the dryline and boundary layer evolution. Mon. Wea. Rev., 135, 2473-2505, doi:10.1175/MWR3453.1.

Campbell, P. C., B. Geerts, and P. T. Bergmaier, 2014: A dryline in southeast Wyoming. Part I: Multiscale analysis using observations and modeling on 22 June 2010. Mon. Wea. Rev., 142, 268-289, doi:10.1175/MWR-D-13-00049.1.

Crawford, T. M., and H. B. Bluestein, 1997: Characteristics of dryline passage during COPS-91. Mon. Wea. Rev., 125, 463-477, doi:10.1175/1520-0493(1997)125<0463:CODPDC>2.0.CO;2.

Demoz, B., and Coauthors, 2006: Dryline on 22 May 2002 during IHOP: Convective scale measurements at the profiling site. Mon. Wea. Rev., 134, 294-310, doi:10.1175/MWR3054.1.

Di Girolamo, P., A. Behrendt, and V. Wulfmeyer, 2006: Spaceborne profiling of atmospheric temperature and particle extinction with pure rotational Raman lidar and of relative humidity in combination with differential absorption lidar: Performance simulations. Appl. Opt., 45, 2474-2494, doi:10.1364/AO.45.002474.

Fujita, T. T., 1958: Structure and movement of a dry front. Bull. Amer. Meteor. Soc., 32, 574-582.

Geerts, B., 2008: Dryline characteristics near Lubbock, Texas, based on radar and West Texas Mesonet data for May 2005 and May 2006. Wea. Forecasting, 23, 392-406, doi:10.1175/ 2007WAF2007044.1.

_- R. Damiani, and S. Haimov, 2006: Finescale vertical structure of a cold front as revealed by an airborne Doppler radar. Mon. Wea. Rev., 134, 251-271, doi:10.1175/MWR3056.1.

Hane, C. E., C. L. Ziegler, and H. B. Bluestein, 1993: Investigation of the dryline and convective storms initiated along the dryline: Field experiments during COPS-91. Bull. Amer. Meteor. Soc., 74, 2133-2145, doi:10.1175/1520-0477(1993)074<2133: IOTDAC $>2.0 . \mathrm{CO} ; 2$.

- H. B. Bluestein, T. M. Crawford, M. E. Baldwin, and R. M. Rabin, 1997: Severe thunderstorm development in relation to along-dryline variability: A case study. Mon. Wea. Rev., 125, 231-251, doi:10.1175/1520-0493(1997)125<0231: STDIRT $>2.0 . \mathrm{CO} ; 2$.

Heaps, W. S., and J. Burris, 1996: Airborne Raman lidar. Appl. Opt., 35, 7128-7135, doi:10.1364/AO.35.007128.

Koch, S. E., and J. McCarthy, 1982: The evolution of an Oklahoma dryline. Part II: Boundary-layer forcing of mesoconvective systems. J. Atmos. Sci., 39, 237-257, doi:10.1175/1520-0469(1982)039<0237: TEOAOD $>2.0 . \mathrm{CO} ; 2$.

Markowski, P., and Y. Richardson, 2010: Mesoscale Meteorology in Midlatitudes. John Wiley and Sons, 407 pp.
Miao, Q., and B. Geerts, 2007: Finescale vertical structure and dynamics of some dryline boundaries observed in IHOP. Mon. Wea. Rev., 135, 4161-4184, doi:10.1175/2007MWR1982.1.

Murphey, H. V., R. M. Wakimoto, C. Flamant, and D. E. Kingsmill, 2006: Dryline on 19 June 2002 during IHOP. Part I: Airborne Doppler and LEANDRE II analyses of the thin line structure and convection initiation. Mon. Wea. Rev., 134, 406-430, doi:10.1175/MWR3063.1.

NSSP Staff, 1963: Environmental and thunderstorm structures as shown by National Severe Storms Project observations in spring 1960 and 1961. Mon. Wea. Rev., 91, 271-292, doi:10.1175/1520-0493-91.6.271.

Parsons, D. B., M. A. Shapiro, R. M. Hardesty, R. J. Zamora, and J. M. Intrieri, 1991: The finescale structure of a west Texas dryline. Mon. Wea. Rev., 119, 1242-1258, doi:10.1175/ 1520-0493(1991)119<1242:TFSOAW>2.0.CO;2.

,-- , and E. Miller, 2000: The mesoscale structure of a nocturnal dryline and of a frontal-dryline merger. Mon. Wea. Rev., 128, 3824 3838, doi:10.1175/1520-0493(2001)129<3824:TMSOAN>2.0.CO;2.

Rhea, J. O., 1966: A study of thunderstorm formation along dry lines. J. Appl. Meteor., 5, 58-63, doi:10.1175/1520-0450(1966)005,0058: ASOTFA.2.0.CO;2.

Russell, R. W., and J. W. Wilson, 1997: Radar-observed "fine lines" in the optically clear boundary layer: Reflectivity contributions from aerial plankton and its predators. Bound.-Layer Meteor., 82, 235-262, doi:10.1023/A:1000237431851.

Schaefer, J. T., 1974: A simulative model of dryline motion. J. Atmos. Sci., 31, 956-964, doi:10.1175/1520-0469(1974)031<0956: ASMODM $>2.0 . \mathrm{CO} ; 2$.

- 1986: The dryline. Mesoscale Meteorology and Forecasting, P. S. Ray, Ed., Amer. Meteor. Soc., 549-572.

Schultz, D. M., C. C. Weiss, and P. M. Hoffman, 2007: The synoptic regulation of dryline intensity. Mon. Wea. Rev., 135, 16991709, doi:10.1175/MWR3376.1.

Sipprell, B., and B. Geerts, 2007: Fine-scale vertical structure and evolution of a preconvective dryline on 19 June 2002. Mon. Wea. Rev., 135, 2111-2134, doi:10.1175/MWR3354.1.

Sun, W. Y., and Y. Ogura, 1979: Boundary layer forcing as a possible trigger to a squall line formation. J. Atmos. Sci., 36, 235-254, doi:10.1175/1520-0469(1979)036<0235:BLFAAP>2.0.CO;2.

Taylor, N. M., and Coauthors, 2011: The Understanding Severe Thunderstorms and Alberta Boundary Layers Experiment (UNSTABLE) 2008. Bull. Amer. Meteor. Soc., 92, 739-763, doi:10.1175/2011BAMS2994.1.

Wakimoto, R. M., and H. V. Murphey, 2009: Analysis of a dryline during IHOP: Implications for convection initiation. Mon. Wea. Rev., 137, 912-936, doi:10.1175/2008MWR2584.1.

, E. V. Browell, and S. Ismail, 2006: The "triple point" on 24 May 2002 during IHOP. Part I: Airborne Doppler and LASE analyses of the frontal boundaries and convection initiation. Mon. Wea. Rev., 134, 231-250, doi:10.1175/MWR3066.1.

Weckwerth, T. M., and Coauthors, 2004: An overview of the International $\mathrm{H}_{2} \mathrm{O}$ Project (IHOP_2002) and some preliminary highlights. Bull. Amer. Meteor. Soc., 85, 253-277, doi:10.1175/BAMS-85-2-253.

Weiss, C. C., and H. B. Bluestein, 2002: Airborne pseudodual Doppler analysis of a dryline-outflow boundary intersection. Mon. Wea. Rev., 130, 1207-1226, doi:10.1175/ 1520-0493(2002)130<1207:APDDAO > 2.0.CO;2.

$\longrightarrow,-$ A. L. Pazmany, and B. Geerts, 2008: Finescale radar observations of a dryline during the International $\mathrm{H}_{2} \mathrm{O}$ Project (IHOP_2002). Synoptic_Dynamic Meteorology and Weather Analysis and Forecasting, Meteor. Monogr., No. 33, Amer. Meteor. Soc., 203-227. 
Whiteman, D. N., G. Schwemmer, T. Berkoff, H. Plotkin, L. RamosIzquierdo, and G. Pappalardo, 2001: Performance modeling of an airborne Raman water vapor lidar. Appl. Opt., 40, 375-390, doi:10.1364/AO.40.000375.

_ , and Coauthors, 2010: Airborne and ground-based measurements using a high-performance Raman Lidar. J. Atmos. Oceanic Technol., 27, 1781-1801, doi:10.1175/2010JTECHA1391.1.

Xue, M., 2002: Density currents in shear flows: Effects of rigid lid and cold-pool internal circulation, and application to squall line dynamics. Quart. J. Roy. Meteor. Soc., 128, 47-74, doi:10.1256/00359000260498789.

_ - and W. J. Martin, 2006a: A high-resolution modeling study of the 24 May 2002 dryline case during IHOP. Part I: Numerical simulation and general evolution of the dryline and convection. Mon. Wea. Rev., 134, 149-171, doi:10.1175/MWR3071.1. and - 2006b: A high-resolution modeling study of the 24 May 2002 dryline case during IHOP. Part II: Horizontal convective rolls and convective initiation. Mon. Wea. Rev., 134, 172-191, doi:10.1175/MWR3072.1.

Q. Xu, and K. K. Droegemeier, 1997: A theoretical and numerical study of density currents in nonconstant shear flows. J. Atmos. Sci., 54, 1998-2019, doi:10.1175/1520-0469(1997)054<1998: ATANSO $>2.0 . \mathrm{CO} ; 2$.

Ziegler, C. L., and C. E. Hane, 1993: An observational study of the dryline. Mon. Wea. Rev., 121, 1134-1151, doi:10.1175/ 1520-0493(1993)121<1134:AOSOTD>2.0.CO;2.

— tion at the dryline: Forecasting issues from a case study perspective. Wea. Forecasting, 13, 1106-1131, doi:10.1175/ 1520-0434(1998)013<1106:TIOMCA > 2.0.CO;2.

, T. J. Lee, and R. A. Pielke Sr., 1997: Convection initiation at the dryline: A modeling study. Mon. Wea. Rev., 125, 1001-1026, doi:10.1175/1520-0493(1997)125<1001: CIATDA $>2.0 . \mathrm{CO} ; 2$. 